\title{
Syntactic Ambiguity as a Device in British Humour
}

\author{
María Teresa Sánchez Roura \\ Universidad de Santiago de Compostela
}

\begin{abstract}
The present study of ambiguity at the syntactic level in the English language focuses on its resourceful applications in the creation of jokes. Such ambiguity is therefore regarded as something to be exploited in language rather than avoided. One important conclusion will be that British humour should not be regarded as "strange" by speakers of other languages, who can only access to it by means of poor, or should we say, difficult translations, since not all types of ambiguity are translatable across languages. The study is divided into three sections, dealing firstly with bracketing of constituents and labelling of categories and functions; and secondly, focusing on transformational relationships, whereby two underlying structures are related to one surface structure. The illustrations are real jokes collected from a variety of popular joke books.
\end{abstract}

British comedy programmes shown on Spanish television often include the studio audience's laughter-something normal in Britain but alien to Spanish programmes. Although such programmes are dubbed into Spanish, and the jokes therefore translated, the average Spaniard probably marvels at how easily the British can be made to laugh, as it is often difficult for him to understand the so-called jokes that the audience is laughing at. The point is, of course, that a great deal of British humour depends on playing with language in different ways, especially exploiting ambiguity at different levels, which is, of course, not always easily translatable. The present study of British humour focuses on ambiguity of a syntactic type. We shall see that such ambiguity may be regarded as something to be exploited in language rather than avoided. This is easily proved: although double interpretations are always potentially present in everyday speech, for one reason or another, one of the two meanings is the "usual" one; it helps the purposes of humour to uncover the other possible meaning. If ambiguity were a serious obstacle in language, everyday communication would be infected by these double meanings, and misunderstandings would be the normal result; however, this does not seem to be the case. Some sort of mechanism within our brains is able to process the correct interpretation, perhaps 
helped by context, or by the language system itself, at each moment, without even giving much thought to the other possible one. Comedians, on the other hand, do bring about the other possibility in order to make people laugh. A study of linguistic ambiguity may provide a useful insight into the nature of language and of parsing processes, which could contribute towards the writing of comedy scripts.

The study is divided into three sections, dealing firstly with bracketing of constituents and labelling of categories and functions; and secondly, focusing on transformational relationships, whereby two underlying structures are related to one surface structure.

\section{Ambiguity due to bracketing}

A characteristic of the English language which is highly productive in terms of humour is the question of attachment of a given element, particularly in the context of the verb phrase, understood here as the whole predicate or "extended verb phrase," where different categories of phrases may be concerned. ${ }^{1}$ Whenever the attachment of such an element, either a whole phrase or just a single word, is possible in different constituents, then ambiguity arises. This type of bracketing has major consequences in that it affects the structure of the whole predicate, especially regarding what counts as a complement of the verb group, and of what kind, and what does not, therefore determining its subcategorization. Differences in bracketing will involve different labellings, both at the phrasal and functional levels.I shall consider two types of ambiguous bracketing, focusing first on those particles ${ }^{2}$ which may be prepositions or adverbs (NP1 part NP2), and secondly on prepositional phrases proper (NP1___ NP2 PP). In the first case, ambiguity results since the attachment of the particle may be to the left, thus forming a phrasal verb, or to the right, forming a prepositional phrase. In the second case, the attachment concerns a PP, which may belong with the verb, either as an adjunct or as a complement, depending on the different verbs selected, or it may be embedded in the NP2.

\section{NP1} part NP2

There are two possible bracketings, as shown in table 1 below. From this, it follows how the two interpretations are so different in terms of syntax and meaning. It is to be noted that the semantic structure of II will depend on the individual verbs selected for the verb slot, since some require a PP as part of their valency and some do not; let us compare, for example, "eat up the road" and "go to the library." It is clearly the case that although both are followed by a PP, "eat" is not subcategorized as a prepositional verb, i.e. the PP does not belong in the valency of the verb since it is not considered a complement but an optional adjunct, whereas "go" does require a PP, and is therefore subcategorized as prepositional (of movement, direction, etc), with the PP belonging in the valency of the verb. Further subcategorizations within one valency will depend on the individual verbs. Let us examine now one example from humour: 
Loy: Let's eat up the street.

Roy: No, thanks; I don't like concrete. ${ }^{3}$

It is obvious that Loy means II whereas Roy makes the joke by taking it as I. The different interpretations may be represented as in table 2 .

\begin{tabular}{|l|l|l|}
\hline Syntactic structure & Semantic structure & Valency \\
\hline I NP1_ NP2 & $\begin{array}{l}\text { I Vb (NP1, NP2) } \\
\text { II NP1_ Vb (NP1, (PP)) }\end{array}$ & $\begin{array}{l}\text { I Verb is divalent } \\
\text { II Verb is monovalent } \\
\text { or divalent }\end{array}$ \\
\hline
\end{tabular}

Table 1

\begin{tabular}{|l|l|l|}
\hline Syntactic structure & Semantic structure & Valency \\
\hline $\begin{array}{l}\text { I NP1 _ NP2 } \\
\text { II NP1_ PP }\end{array}$ & I Vb (NP1, NP2) & $\begin{array}{l}\text { I Verb is divalent: transitive } \\
\text { phrasal } \\
\text { II Verb is monovalent: } \\
\text { intrans. or object-deleting. }\end{array}$ \\
\hline
\end{tabular}

Table 2

NP1 NP2 PP

There are three possible bracketings, shown in table 3 below:

\begin{tabular}{|l|l|l|}
\hline Syntactic structure & Semantic structure & Valency \\
\hline I NP1 _ NP2 PP & I Vb (NP1, NP2) & I Verb is divalent \\
II NP1__ NP2 & II Vb (NP1, NP2) & II Verb is divalent \\
III NP1_ NP2 PP & III Vb (NP1, NP2, PP) & IIIVerb is trivalent \\
\hline
\end{tabular}

Table 3

Under the first interpretation, the PP is an adjunct, which means it does not belong to the valency of the verb, so that the verb is divalent, with an optional element added; under the second one, the PP is included in the previous NP, therefore the verb is also divalent; under the third, the PP is a prepositional complement, belonging to the valency of the verb, classing this as trivalent. Further subcategorizations will depend on the individual verbs. Ambiguity may arise between any of the three structures, although the examples which I have found in humour contrast only two of the three interpretations: that between I and II (i.e. regarding the attachment of the PP to the preceding NP or not, thus being optional), 
and between I and III (i.e. regarding the PP as an adjunct or a complement), the former being the most popular one by far. Consider the following example:

Waiter: We have almost everything on the menu.

Customer: I can see that. Will you please bring me a clean one?

The waiter obviously means II, and the customer makes the joke by taking it as I. The interpretations are shown in table 4:

\begin{tabular}{|l|l|l|}
\hline Syntactic structure & Semantic structure & Valency \\
\hline I NP1 _ NP2 PP & I Vb (NP1, NP2) & I Verb is divalent: \\
II NP1_ NP2 & II Vb (NP1, NP2) & $\begin{array}{l}\text { II Verb is divalent: } \\
\text { transitive }\end{array}$ \\
\hline
\end{tabular}

Table 4

Another example, now contrasting I and III is the following:

Teacher, to Sam, who had just knocked Mac down: Sam, did you also strike Mac in the excitement?

Sam: No, sir, I struck him in the stomach.

The teacher means the first syntactic interpretation, with "in the excitement" as an adjunct, whereas Sam takes it as III with the same phrase as a prepositional complement of the verb "strike." This may be represented in table 5 as follows ${ }^{4}$ :

\begin{tabular}{|l|l|l|}
\hline Syntactic structure & Semantic structure & Valency \\
\hline I NP1_ NP2 PP & I Vb (NP1, NP2) & I Verb is divalent: \\
II NP1_ NP2 PP & II Vb (NP1, NP2, PP) & $\begin{array}{l}\text { transitive } \\
\text { II Verb is trivalent: } \\
\text { transitive-prepositional }\end{array}$ \\
\hline
\end{tabular}

Table 5

\section{Ambiguity due to labelling}

Labelling is the process by which characteristics of the constituents of the sentence are given, at two levels: the morphological one, or category labelling, both of lexical and phrasal categories, which is something inherent to words; the syntactic one, or function labelling, of phrases within the sentence and of lexemes within the phrase. This is established in terms of the relations that words establish among themselves. Ambiguity 
due to labelling arises from the fact that there is not a one-to-one correspondence between categories and functions, and from the multi-membership of many words into different lexical categories. Categories and functions are not in a one-to-one correspondence, neither at sentence level (one phrase may perform different functions within the sentence, and vice versa, one function may be realized by different phrases), nor at phrase level (one lexeme may perform different functions within the phrase, and vice versa, one function may be realized by different lexemes). However, there tends to be a prototypical relationship between category and function, the assumption of which in people's minds gives rise to innumerable jokes, which start from the "logical or "natural" version and deviate from it into the other possible alternative in order to make the joke; for example, consider the following "innocent" question that a son asks his mum in the kitchen: "How do you make an apple puff?"; bearing in mind the answer of the witty child we realize the ambiguous nature of the question in the first place: "Chase it round the garden!" Let us consider now the two levels of labelling in more detail.

\section{Category labelling: lexical and phrasal categories}

The majority of grammarians agree with the distinction of the following parts of speech for the English language: noun, adjective, verb, adverb, pronoun, article, preposition and conjunction. A division is usually made between "major" and "minor" parts of speech, on the basis of whether a lexical or grammatical category belongs to that group. Brown and Miller explain this distinction:

[L]exical categories are realized either as free forms (e.g. dog, walk) or as the stems of complex forms (e.g. dog-s, walk-ing). Grammatical categories, on the other hand, are very often realized as bound forms (e.g. -s, -ing, -ed), though they may on occasion be realized as individual words (e.g. the auxiliary verbs) ... The fact that grammatical categories are often realized as bound morphemes leads, in many languages, to a typical association between a lexical category and a grammatical category or categories. So, for example, in English the category Number is realized on the Noun, and the category of Tense is realized on the Verb. ... (232)

It is considerations of this sort, they argue, that "lie behind the establishment of a system of parts of speech for a language." Criteria used to classify the parts of speech involve inflectional and syntactical issues, or as Huddleston puts it "any satisfactory account of the parts of speech must make clear that the classification depends on the grammatical function and form of words in sentences" (93). On the other hand, however well defined these may be, the sets of parts of speech are bound to be conflictive, because of having either too many or too few elements fulfilling the criteria used in defining them. As Brown and Miller point out "we can establish a class of 'central members' that meet all or most of the criteria. There remain various sub-classes that meet the criteria to a greater or lesser extent, or, on the margins, hardly at all!" (235). Huddleston also refers to the distinction between "prototypical or central members" and the "more or less marginal" ones, by saying that the account of parts of speech must recognize this distinction, and also "the 
possibility of some indeterminacy over just where the boundaries are to be drawn" (93). Not only this, but he goes further, trying to establish the difference between words of one class occurring "with a function which is prototypically associated with another class" (96), and words which do belong in different classes. ${ }^{5}$

Labelling lexical categories results in ambiguity if: (1) one word fulfills inflectional and syntactical criteria applicable to more than one class; ${ }^{6}(2)$ the ending of one word makes this belong to different parts of speech. This ending may be a grammatical one, or just the mere end of the root. ${ }^{7}$ Let us see some examples from humour, where ambiguity arises due to the first principle ${ }^{8}$ :

Teacher: Sally, you're pretty dirty.

Sally: Yes; and I'm even prettier when I'm clean. ${ }^{9}$

The second principle is not as productive as the first one in humour. Consider, though, the following example:

What did the woodworm say when he went to the pub?

Is the bar tender here?

Some jokes are based on a combination of morphological and syntactic processes, such as the following:

Etta: Did you hear about the kidnapping in Kent?

Gretta: No; what happened?

Etta: They woke him up.

Although the relationship between lexical and phrasal categories is in a one-to-one correspondence, since lexical categories give rise to phrases "of their own"-i.e. the lexical category is the head of the new phrase-ambiguity results since a word may be the head of more than one type of phrase, by virtue of its possible membership to different parts of speech as mentioned above. According to Huddleston, the head is obligatory and it imposes restrictions on what kinds of forms can occur as dependents (109); therefore, we shall find most examples of these in cases where the phrase is only that one word, since expansion of the phrase often results in the repair of the ambiguity, as the type of dependents taken vary between classes of speech. However, expansion of the sentence-i.e. at higher levels of organization-may preserve the ambiguity since it may not affect so much the syntax of the actual phrase involved. Consider the sequence: "She looked hard," where "hard" is either an adjective or an adverb, and as a phrase it is an adjectival phrase, as well as an adverbial one, both of which are perfectly valid as complements of "look." Expansions of the sentence ("She looked hard when she came in"), even of the adjectival/adverbial phrase ("She looked very hard") may respect the ambiguity; whereas expansion of the verb phrase itself repairs the ambiguity ("She looked hard at the floor"). The important issue resulting from ambiguous phrasal labelling is the effect that this has on the surrounding environment. In the above example, "look" may be 
further subcategorized as intensive if "hard" is an adjectival phrase, or as object-deleting, if an adverbial phrase. Moreover, changes of verb subcategorization may also be accompanied by changes of meaning, varying in different degrees, like in "look" above. Finally, let us consider one more ambiguous example, in which lexical and phrasal labelling combine with bracketing processes: "They can fish."

\section{Function labelling: with special reference to the VP}

Once the constituents of the sentence have been labelled, one should turn to see what their functional relations are. We may say that a VP is composed of V+NP, but it is certainly the case that not all VP's of that structure are indeed the same. Functional relations are at work, and the distinction between them contributes decisively to the final meaning of the sentence. Since VP's of the above structure, for example, may be of different sorts in virtue of the different functional relations between $\mathrm{V}$ and NP, ambiguity is bound to emerge, which may also affect the further subcategorization of the verb, not so much its valency, since a $\mathrm{VP}=\mathrm{V}+\mathrm{NP}$ is almost always at least divalent, but the subcategorization of the verb as, for example, transitive or intensive. I shall focus my analysis of functional relations on four concrete environments within the VP.

1. NP $\emptyset$, where the absent phrase may prove a case of intransitiveness or of object deletion.

2. NP1 NP2, where the NP2 may prove to be related to the verb in different ways; for example, by being its direct object, its objoid, cognate object, or even an adverbial. 3. NP1 NP2 NP3, where NP2 and NP3 may also be functionally related in different ways; for example, they may be indirect and direct objects, or intensive complements, to either the subject or the object. It may also be the case that one of the two postverbal NP's may be omitted.

4. NP1 NP2/AP1. This is a special case in comparison with the above, since the actual structure shown for the ambiguous sequence is, in fact, not one but two. However, the two postverbal phrases may be easily mistaken, especially in a question, where both NP and AP may be substituted by "what."

Let us now examine these in more detail.

1. NP $\varnothing$

\begin{tabular}{|l|l|l|}
\hline Syntactic structure & Semantic structure & Valency \\
\hline $\begin{array}{l}\text { I NP1 } \\
\text { II NP1 }\end{array}$ & I Vb (NP1) & $\begin{array}{l}\text { I Verb is monovalent: } \\
\text { intransitive } \\
\text { II Verb is divalent: } \\
\text { object-deleting }\end{array}$ \\
\hline
\end{tabular}


Stern Librarian: Please, be quiet! The people near you can't read.

Small Boy: Why, they ought to be ashamed of themselves! I've been able to read since I was six.

The librarian means "read" in the object-deleting sense, whereas the child interprets it in the intransitive sense. ${ }^{10}$

2. NP1 NP2

\begin{tabular}{|l|l|l|}
\hline Syntactic structure: & Semantic structure & Valency \\
\hline I NP1 _ NP2 & I Vb (NP1, NP2) & I Verb is divalent: \\
II NP1_ NP2 & II Vb (NP1, NP2) & $\begin{array}{l}\text { II Verb is divalent: } \\
\text { transitive }\end{array}$ \\
\hline
\end{tabular}

Table 7

Sam: In Aberdeen there is a butcher who is 29 years old, and 5 feet 6 inches tall; he wears a size 8 hat, and size 9 shoes. What does he weigh?

Ham: I give up; what?

Sam: Meat, of course!

After such a long and confusing presentation of the butcher, Ham is bound to take the question in the objoid sense, whereas it is really meant in the object one. ${ }^{11}$

3. NP1 NP2 NP3

I shall divide this category into two sections: (a) where the two postverbal NP's are present; and (b) where one of them is deleted.

(a) NP1 NP2 NP3

\begin{tabular}{|l|l|l|}
\hline Syntactic structure & Semantic structure & Valency \\
\hline I NP1 N NP2 NP3 & I Vb (NP1, NP2, NP3) & $\begin{array}{l}\text { I Verb is trivalent: } \\
\text { ditransitive } \\
\text { II NP1_Nerb is trivalent: } \\
\text { II Vb (NP1, NP2, NP3) } \\
\text { complex-transitive } \\
\text { (whether referring to } \\
\text { subject or object) }\end{array}$ \\
\hline
\end{tabular}


Let us examine one example from the literature, since this is not a very productive area in the formation of jokes:

Mary made \{John\} \{a good cake/husband/wife $\}$

Under I NP2 is the indirect object and NP3 is the direct one, the verb being ditransitive; under II NP2 is the indirect object and NP3 is an intensive complement of the object or the subject, the verb being complex-transitive. Notice that functions and subcategorizations depend on the lexical item chosen for the NP3 slot.

(b) NP1 NP2

\begin{tabular}{|l|l|l|}
\hline Syntactic structure & Semantic structure & Valency \\
\hline I NP1_NP2 & I Vb (NP1, NP2) & I Verb is divalent: \\
II NP1_NP2 & II Vb (NP1, NP2, NP3) & $\begin{array}{l}\text { II Verb is trivalent: } \\
\text { ditransitive }\end{array}$ \\
\hline
\end{tabular}

Table 9

Note that under I NP2 is a simple direct object, but under II it may be the indirect object of the ditransitive verb, with the direct one omitted, or the direct object with the indirect one elided. Consider the following example:

First Cannibal: What book are you reading?

Second Cannibal: It's called "How to serve your fellow-man."

Under the "cannibal" interpretation, "serve" exhibits the structure in II, and it may be subcategorized as ditransitive, in the sense that "something is served to someone," with the indirect NP missing; under the more humanistic interpretation, it exhibits the structure in I, with "serve" as a transitive verb. Note that the different subcategorization is linked to a change in meaning. ${ }^{12}$

\section{NP1} NP2/AP

This type of ambiguity is of a different sort, since it is not based on one and the same phrase performing two different functions, but on two different phrases fulfilling those different functions. However, it comes under this section because in some cases both phrases may be identified with each other, particularly in questions and in one-word phrases.

What does a hard-working gardener grow?

Tired! 
Under I in table 10 below the question is meant transitively, whereas the answer corresponds to the structures shown in II, with the verb as inchoative. This ambiguity is also particularly effective with "get," and I would like to include here one joke which is structurally the same as the above, but especially amusing in my opinion, since it mocks the never-ending string of "what-do-you-get-if-you-cross" riddles:

What do you get if you cross the M1 with a skateboard?

Run over! $!^{13}$

\begin{tabular}{|l|l|l|}
\hline Syntactic structure & Semantic structure & Valency \\
\hline I NP1 NP2 & I Vb (NP1, NP2) & $\begin{array}{l}\text { I Verb is divalent: } \\
\text { transitive } \\
\text { II NP1_ AP1 }\end{array}$ \\
II Vb (NP1, AP1) & $\begin{array}{l}\text { II Verb is divalent: } \\
\text { intensive (inchoative) }\end{array}$ \\
\hline
\end{tabular}

Table 10

The following example is the same as the two above, but it is not expressed in question form:

During a crucial moment in the game, the coach looked down the long line of substitutes on the bench, and yelled heartily: "All right, Jones, go in there and get ferocious!" Jones: “OK, sir; what's his number?”

The coach means his sequence in the inchoative sense, and Jones interprets it in the transitive one, as if "ferocious" was the name of a rival player.

\section{Ambiguity due to transformational relationships}

Sentences of the type

I John loves Mary

II Mary is loved by John

were described as transformationally related in grammars of the seventies and early eighties. For example, Huddleston describes transformations as those "changes applied to the structure of an unmarked form to yield a marked form" (14). The cases with which I shall deal in this section are each the result of transforming one or two sentences of a set of two different basic unmarked forms into one and the same sentence, which can be analyzed syntactically (bracketed) and morphologically (labelled) in different ways, i.e. the resulting sentence is ambiguous because of transformational relationships. Along these lines, Lyons discusses transformational ambiguity, and defines a sentence as transformationally ambiguous "if and only if it is derived from two or more distinct 
underlying structures" (403). Therefore, it should be noted that my use of the term "transformational" is not in line with the current use in grammars of the late eighties and early nineties, but that it is used informally.

\section{1. "-ed" ending}

This type of ambiguity based on an "-ed" form arises from the fact that two different underlying structures coincide on the surface because one of them is transformed and the other one is left unchanged but for which a special set of elements has been selected

$$
\begin{aligned}
& \mathrm{INP}+\mathrm{V}+\mathrm{NP} \rightarrow \mathrm{NP}+\text { be }+\mathrm{V}(\text { ed })+(\text { Ag. }) \\
& \text { II } \mathrm{NP}+\mathrm{V}+\text { Predicative } \rightarrow \mathrm{NP}+\mathrm{V}+\text { Predicative }
\end{aligned}
$$

where $I$ is an active sentence which is transformed into the passive, representing an activity, and II is, and remains, an active sentence, representing a state; both of these coincide in the selection of the item to occupy the first verb slot ("be," which is an auxiliary verb in I and a main verb in II) and the slot immediately following this (an "-ed" form, which is the passive participle resulting from the transformation in $I$, and an adjective in II). Therefore, we encounter a transformation of $I$ and a special selection of elements for II, which coincide on the surface, yielding the following structure:

$$
\text { NP + be + "-ed" form }
$$

\begin{tabular}{|c|c|c|}
\hline Syntactic structure & Semantic structure & Valency \\
\hline $\begin{array}{l}\text { I NP1 } \\
\text { II NP1 }\end{array}$ & $\begin{array}{l}\text { I Vb (NP1) } \\
\text { II Vb (NP1, AP) }\end{array}$ & $\begin{array}{l}\text { I } \mathrm{Vb} \text { is monovalen } \\
\text { II } \mathrm{Vb} \text { is divalent }\end{array}$ \\
\hline
\end{tabular}

The syntactic and semantic structures may be seen in the following table:

Table 11

Let us now see one example taken from humour, where these differences and similarities are exploited:

Have your eyes ever been checked? ${ }^{14}$

No, they've always been blue.

The two interpretations of the ambiguous sentence are present in the joke, since person A means the passive one, intransitive on the surface, (although transitive deep down), and person B makes the joke by taking A's question as active, intensive, with "checked" as an adjective. $^{15}$ 
2. “-ing" ending

This type of ambiguity based on an "-ing" form is two-fold: (a) one refers to the distinction between "-ing" as a verb or a noun, (b) the other one, to the distinction between "-ing" as a verb or an adjective.

(a) “-ing" as a verb or a noun

Within this category, two further subdivisions need to be made, on the basis of surface bracketing. This depends on whether the "-ing" form is dependent on the the verb "to be" or on any other.

(a)1. If following the verb "to be," then it is the case that there are two different underlying structures, one of which is transformed aspect-wise, the other one being left unmarked, both of which coincide on the same surface string, but not on its bracketing:

$$
\begin{aligned}
& \text { I NP + V } \rightarrow \text { NP + be }+ \text { V(-ing) } \\
& \text { II NP + V + Pred }
\end{aligned}
$$

where I is a sentence in a simple tense, which is transformed into the progressive form, and II is an unmarked sentence, for whose $\mathrm{V}$ and Pred. "Be" and an "-ing" noun may be selected. Therefore, we encounter a transformation of I and a special selection of elements for II (which remains unmarked), both coinciding on the surface:

$$
\mathrm{NP}+\mathrm{be}+\text { "-ing" form }
$$

As with the "-ed" case, the differences shown in the diagram are those at the underlying level, but there also some at the surface grammatical level, concerning "be"and the "-ing" form. Under I "be" is the auxiliary for the formation of the progressive and the "-ing" is the present participle of the main verb; under II "be" is the main verb, and the "-ing" form is a noun; I represents an activity, II represents a state. Let us examine now one example of this taken from humour ${ }^{16}$ :

What did the egg mayonnaise say to the fridge?

Close the door, I'm dressing.

\begin{tabular}{|l|l|l|}
\hline Syntactic structure & Semantic structure & Valency \\
\hline $\begin{array}{l}\text { I NP1 — NP2 } \\
\text { II NP1 }\end{array}$ & I Vb (NP1) & $\begin{array}{l}\text { I Vb is monovalent } \\
\text { II Vb (NP1,NP2) }\end{array}$ \\
\hline
\end{tabular}


Syntax and semantics differentiate the two interpretations, as well as produce a different subcategorization of the verb "be."

(a)2. If following any other verb, then it is the case that there are two nderlying structures, which are both transformed by ellipsis of the subject argument of the "-ing" form, both of which are different. The resulting surface structure shows only one syntactic bracketing, and two different labellings.

$$
\begin{aligned}
& \text { I } \mathrm{NP} 1+\mathrm{V} 1+\mathrm{NP} 1+\mathrm{V} 2 \rightarrow \mathrm{NP} 1+\mathrm{V} 1+\mathrm{V} 2 \\
& \mathrm{II} \mathrm{NP} 1+\mathrm{V} 1+\mathrm{NP} 2+\mathrm{V} 2 \rightarrow \mathrm{NP} 1+\mathrm{V} 1+\mathrm{V} 2 \\
& \text { Note: } \mathrm{V} 2=- \text { ing }
\end{aligned}
$$

The difference between them lies in the fact that V2 in I represents an activity, realised by the same subject of V1, and in II V2 represents a "thing," or activity realised by a different subject. Let us examine one example, this time taken from the literature (Huddleston 314): "I like singing," where under I “*I like I sing," and under II "*I like you/others sing."

(b) -ing as a verb or an adjective.

The underlying sentences which yield this type of distinction correspond to the transitive or intransitive character of the verb on which the -ing form is made. It is the transitive interpretation that yields the -ing as a verb, and the intransitive as an adjective. The most well-known example of this sort is Chomsky's very much quoted:

Flying planes can be dangerous

on which I shall make no further comment, except to say that the bracketing of "flying planes" is the same for both interpretations, with different labelling of course, which depends on whether the sequence proceeds from I the transitive version ("to fly planes"), or II the intransitive one ("planes that fly"), with "flying" as a verb or adjective respectively. I shall examine, however, a similar example taken from humour:

What's worse than raining cats and dogs?

Hailing taxis! ${ }^{17}$

Under I "hailing" is intransitive, meaning "taxis that hail," by analogy with "cats and dogs that rain," as it were; under II "hailing" is transitive, meaning "to hail taxis," obviously now with a different meaning of "hail." We may represent this in table 13 below:

\begin{tabular}{|l|l|l|}
\hline Syntactic structure & Semantic structure & Valency \\
\hline I NP1 & I Vb (NP1) & I Vb is monovalent \\
II NP1 & II Vb (NP1,NP2) & NP divalent \\
\hline
\end{tabular}


As with "-ing" as a verb or a noun, within "-ing" as a verb or an adjective a separate mention may be made of the "-ing" depending on the verb "to be." The situation is exactly the same as in verb/noun.

$$
\begin{aligned}
& \text { I NP + V } \rightarrow \text { NP + be + V(-ing) } \\
& \text { II NP + V + Pred }
\end{aligned}
$$

where $\mathrm{I}$ is a sentence in a simple tense form, which is transformed into the progressive, and II is an unmarked sentence, for whose V and Pred, "be" and an "-ing" adjective may be selected. Therefore, we encounter a transformation in I and a special selection of elements for ii, which remains unmarked, both coinciding on the surface:

$$
\mathrm{NP}+\text { be }+ \text {-ing form }
$$

Once again, there are also differences at the surface grammatical level: "be" is an auxiliary in I, and a main verb in II; The "-ing" form is the present participle of the main verb in I, and an adjective in II; I represents an activity, II represents a state.The following is an example taken from humour:

Miss Wornout wrote on Bobby's report: "Bobby is trying-very."

The two interpretations are represented in table 14:

\begin{tabular}{|l|l|l|}
\hline Syntactic structure & Semantic structure & Valency \\
\hline I NP1 & I Vb (NP1) & $\begin{array}{l}\text { I Vb is monovalent } \\
\text { II NP1_ AP }\end{array}$ \\
\hline
\end{tabular}

Table 14

Again, syntax and semantics, with valency, show clearly the differences at the surface and underlying levels between the two structures.

\section{Conclusions}

The above description of English syntactic ambiguities, illustrated with examples taken from humour, suggests further lines of thought.

I. About the nature of language. Aristotle is quoted by Kooj on the subject of the ambiguous nature of language: "For names are finite, and so is the sum-total of formulae, while things are infinite in number. Inevitably, then, the same formula, and a single name, have a number of meanings." If by "formula" a syntactical structure may be understood, then both labelling and bracketing ambiguities are involved here, and considered as 
inherent to language. What types are more inherent than others, and whether languages differ and in what degrees as far as ambiguity is concerned, are matters of argument among the specialists. It is clearly the case that some of the jokes will translate into Spanish, for example, and some will not. What is at the heart of the matter is the fact that some types of ambiguity are common to both languages and others are not; therefore, we may infer that those which are translatable as ambiguous in the other language may be more inherent to language in general, as a system and not as a lexicon, whereas those which do not translate show signs of not being inherent to language but are a characteristic of that particular language (i.e. system and lexicon). And there is, in fact, a clear division, in the light of the data, between these: cases of bracketing will translate as ambiguous into Spanish, whereas cases of labelling will not. ${ }^{18}$ This could be interpreted as meaning that bracketing ambiguity, which refers to the formulae, is more inherent to language, i.e. is bound to occur, and also, more often, since the number of rules is in fact limited and cannot be extended; whereas labelling ambiguities are the result of a limited lexicon, which, no doubt, could be extended, either by adding new words, or by developing, or not letting die, a grammatical case-ending system, or the verb conjugation. In this sense, labelling ambiguity is less inherent to language, in that it can be more easily avoided and in that its occurrence varies so much across languages (for example, in Spanish there is not a word which is a noun and a verb at the same time, at least not in the same way as in English). This tentative idea could have important side effects in everyday life, and in relation to humour. The possibility occurred to me that, since bracketing ambiguity may be translated as ambiguous into Spanish, then jokes based on this phenomenon are guaranteed to be also a joke in Spanish, whereas those based on labelling are not. Therefore, one could advise the author of a comedy programme to choose word-plays based mostly on bracketing ambiguities in order to succeed whenever those programmes are sold abroad and dubbed.

One further matter on the nature of language is the discussion about whether ambiguity is to be considered as something to be avoided or as something to be pursued. In my opinion it may be both, although in the majority of cases it is neither. Ambiguity is an obstacle whenever it is present in communication producing a misunderstanding; if nothing can repair it, then faulty communication results. This is often the case in notices and advertisements, where there is no one at the other end of the message, i.e. the sender, to repair it: I heard about a man who thought he could not use the tube in London because he did not have a dog; he had read the notice: "Dogs must be carried on a lead." However, if both sender and receiver are present at the moment of communication and ambiguity is perceived, then it is usually repaired by paraphrase. Ambiguity is a device in that two ideas may be expressed with economy of words. In everyday speech, people who are able to perceive these ambiguities, or to provoke them, are considered clever or witty, and this is very popular, as I have observed, among English people. Publicity also makes use of ambiguities of some sort or other in order to give more weight to their advertisement, to express more than one idea with few words, and so that the slogan is considered clever (for example: "Bypass Nurseries: Growing better for you"). As one of the advocates of ambiguity as a device puts it, "an ambiguity, in ordinary speech, means something very pronounced, and as a rule witty or deceitful (Empson 1)." Not only everyday 
communication benefits from the phenomenon, but poets consider it a valuable resource. Empson goes even further to affirm that all good poetry is supposed to be ambiguous (XV). However, in spite of the fact that ambiguous instances occur all the time in everyday communication, they pass unnoticed most of the time, being automatically repaired by context. Bally, who is quoted by Kooj (4), expresses the view that "ambiguity, though inherent to natural language, should not be overrated as an actual obstacle in communication: most ambiguitites will automatically be resolved by verbal context or by the situation in general in which communication takes place."

II. About parsing processes. If one observes the way in which the ambiguous jokes in the data are developed, one may discover interesting aspects about the way people interpret language. The procedure is usually one of the following two: the ambiguous sentence is offered, with version A in mind; but version B is taken as the logical one, until one discovers version $\mathrm{A}$ is also possible. This is what is usually referred to as garden pathing. I shall not enter here into the detail of what determines one structure to be the logical one. Alternatively, the ambiguous sentence is offered, and both versions $A$ and $B$ can be taken at the same time. This is a parallelism. The fact that there tends to be a "logical" version, which is preferred to the other alternative, seems to prove that ambiguity does not really exist in context. On the other hand, the fact that a joke may be made may prove the contrary: that ambiguities are at work, in this case as a device to raise a smile—or a groan!

\section{Notes}

1. Bracketing within the noun phrase is not considered here since it has been found not to be very successful in the production of jokes. The ambiguity which may arise from bracketing in the NP is, in many cases, either a mere question of emphasis (cf. "a nice blue carpet," meaning either "the blue carpet is nice" or "the carpet is a nice blue"), or is more easily repairable by context (cf. "our old garden lawn" and "our old garden fence"). Furthermore, this type of ambiguity when presented orally is more readily repaired through intonation.

2. Some phrasal verbs take adverbs and not prepositions; however, some authors consider these particles as prepositions, on the basis that they may take a zero-phrase as a complement. Ambiguity arises in the environment "verb + particle + NP," where the particle is either an adverb or a preposition with a zero-phrase, but with an NP following which may easily be taken as the complement of that particle, when it is really something else.

3. Further examples, posing different problems for your consideration, are:

-Did you hear about the boy who ran away with a circus?

- The policeman made him bring it back.

Silly Sally and Vague Vera were talking about their resolutions for the New Year. Sally giggled suddenly and asked: "Do you know why New Year resolutions are like fat ladies who faint in a church?" Vera shook her head vaguely, and asked: "No, why?" Sally giggled again: "Because the sooner they are carried out the better." 
Haughty Lady: Must I stick the stamp on myself?

Haughty Clerk: I think you"ll accomplish more, madam, if you stick it on the package.

Customer: Do you have any wall-paper?

Assistant: Lots of it.

Customer: Can I put it on myself?

Assistant: Well, yes; but it looks better on the wall.

Doctor, doctor, my hair keeps falling out; can you suggest anything to keep it in?

How about a cardboard box?

4. Further examples, posing different problems regarding the attachment of a PP in the VP are:

Safari guide: Quick sir, shoot that leopard on the spot.

Idiot hunter: Be specific, you fool; which spot?

Patient: Doctor, doctor, I've broken my arm in several places.

Doctor: You should stop going to these places, then.

-Your dog's been chasing a man on a bicycle.

-Don't be stupid! My dog can't ride a bike.

- How do you stop your dog barking in the hall?

-Put it outside.

Son: Can I go out and play?

Mother: What! With those dirty trousers?

Son: No, with Tom next door.

5. An important note should be made here. A change in class may result in a change in meaning, whether this be related (e.g. "fish" as verb or noun) or totally unrelated (eg. "utter," as verb or adjective). I shall take both into consideration, since the change of meaning is accompanied by a change in part of speech, and this in turn may imply a change in function; otherwise those examples should not be included under "grammmatical ambiguity," but "Iexical ambiguity." Therefore, "ball" 1 and "ball" 2 are not brought into this study, since there is no change in part of speech, only in meaning.

6. For example, "long," "secret," "fast," "fine." These examples are usually accounted for by the grammarians in terms of either conversion or zero affixation. The most common one, and so typical of the English language, is that of a word being both a verb and a noun, taking the inflections of both, and fulfilling the functions of both.

7. Examples: “-s, -ed, -er, -ing, -en." These endings are considered in their grammatical functions. It should be borne in mind that a word may end in one of these, with the ending being part of the root morpheme of the word, and therefore belonging in a different class "by pure chance." For example, "-s" grammatically yields a noun in the plural and a third person singular of the simple present tense. However, a word ending in "-s," as morpheme final, may be an adjective ("ludicrous"), a mass noun ("gas"), an adverb ("afterwards"), etc.

8. Further examples are: 
-Why didn't the skeleton go to the party?

-Because he had no body to go with.

-Waiter, will my hamburger be long?

-No sir, it will be round and flat.

Teacher: I wish you would pay a little attention.

Girl: I'm paying as little as possible.

Officer: Boy, you can't park by the hydrant.

Dopey Dan: Why not? The sign says "fine for parking."

Next-door neighbour to small boy: Come again, Johnny. We'd like to see more of you. Johnny: But there isn't any more of me!

9. Note that the different examples may be further re-enforced by alternative bracketing of constituents, and that, inversely, ambiguity may be more easily repairable by means of intonation.

10. Further examples of this are:

-What is the best way to keep fish from smelling?

-Cut off their noses.

-Mrs. Newcomer wrote a disgusted note of complaint to the teacher of her son's class at his new school. She ended the letter with: "If all our Benjamin learns from you is how to swear, I will keep him at home and teach him myself!"

-What gets wet as it dries?

-A towel.

11. Further examples are:

Mum: During the last year my boy has grown another foot.

Neighbour: Remarkable; on his left leg or on his right one?

Mike: If you had a gun with one bullet, and a tiger was coming in one direction and a lion from the other, which would you shoot?

Spike: The gun!

A group of tourists in an Austrian city were dining in a restaurant. One of the musicians started playing a haunting, vaguely familiar melody, buy none of them could recall its name. They called the magnificiently clad waiter over, and asked him to find out what the musician was playing. He padded across the dining-room, and then returned in triumph to announce: Violin!

12. Further examples are:

Customer: Do you serve lamb? 
Waiter: I'm sorry. sir; we don't allow animals to dine here.

Customer: How do you serve shrimps here?

Waiter: We bend down.

-What did the barman say to the ghost in his bar?

- Sorry, we don't serve spirits here.

Notice that some of these jokes are further re-enforced by lexical ambiguity (cf. "shrimp" and "spirits").

13. Obviously, the polysemy of "cross" is a great help in the success of this particular example.

14. Notice the polysemy of the word "checked," which re-enforces the ambiguity posed by the transformational relationship between both underlying structures. This example is included here since a change in part of speech is involved.

15. Further examples for your consideration are:

Benny: Your girl is delightfully outspoken.

Lanny: Really? By whom?

-Why can a leopard never get out of the zoo?

-Because it's always spotted.

16. Further examples are:

-What's black and white and stops buses?

-A zebra crossing.

-When is water like fat?

-When it's dripping.

17. Note that this example is further re-enforced by the polysemy of "hail."

18. Remember that while bracketing within the NP was considered as not particularly interesting from a linguistic point of view, (see footnote 1), the same phenomenon within the VP seems to me a very productive and interesting area of syntax. Confusions and doubts as to the attachment of the final PP where an intervening NP occurs give rise to innumerable applications in humour, and also to misunderstandings in real life communication. Moreover, this particular type of ambiguity may be translated as ambiguous more easily than others into another language, such as Spanish for example, with the result that jokes based on this phenomenon will be successful when translated, thus guaranteeing the same English laughter, or groan, into the other language. Obviously, by success I mean from a linguistic point of view-social and cultural factors have an important say in the development of humour across cultures. 


\section{Works Cited}

Brown, E. K., and Miller, J. E. Syntax: A Linguistic Introduction to Sentence Structure. London: Hutchinson, 1980.

Empson, W. Seven Types of Ambiguity. London: Chatto and Windus, 1947.

Huddleston, R. Introduction to the Grammar of English. Cambridge: Cambridge UP, 1984.

Kooj, J. G. Ambiguity in Natural Language. Amsterdam: North-Holland, 1971.

Lyons, J. Semantics. Cambridge: Cambridge UP, 1977.

Various assorted joke books, of which unfortunately I have not the complete details, have been used in order to compile the corpus of data:

Blundell, N. The Loud Raspberry.

Brown, M. Joke Book.

Hogart, J. Not the Elephant Joke Book.

Hoke, H.. Laughs, Laughs, Laughs.

Howard, B. Writing Jokes and Riddles.

Leadercramer, A., and R. Morris. Chuckle, Chuckle.

Rothman, J. The I Luv Skool Joke Book. 